\title{
Numerical Analysis on Premixed Flame Propagation in Acoustic Field
}

\author{
By Takuma YANO $^{1)}$, Takuo KUWAHARA ${ }^{2)}$ and Mitsuaki TANABE ${ }^{2)}$ \\ ${ }^{1)}$ Graduate school of science and technology, Nihon university, Chiba, Japan \\ ${ }^{2)}$ College of science and technology, Nihon university, Chiba, Japan
}

(Received May 2nd, 2008)

\begin{abstract}
The influence of an acoustic field on premixed flame propagation was examined by numerical simulation and experiment. The influence was evaluated from the two points of view. One is the diffusive transport and the other is convective transport. The particle oscillation by sound is considered to increase diffusivity in the acoustic field like turbulent diffusion. The thermal convection occurs when the density difference exists in the acoustic field. It is considered that flame front is deformed by this thermal convection. To analyze the diffusive and convective influence of the acoustic field, experiment and numerical simulation with strong standing wave had been made. To evaluate the influence of the thermal convection, buoyancy-induced natural convection was removed. As the result, the effect of the thermal convection is clearly observed in both experiment and numerical simulation when the sound pressure level is above 150dB. And the numerical simulation results agreed with experimental results. The burning velocity changes in the acoustic field. The effect is significant especially for a flame that propagates perpendicular to the particle oscillation.
\end{abstract}

Key Words: Acoustic Streaming, Combustion Oscillation, Premixed Flame

\section{Nomenclature}

$f \quad$ :frequency

$m \quad$ :rate of consumption of unburned gas mixture

$S \quad$ :burning velocity

SPL :sound pressure level

$u$ :amplitude of velocity oscillation

$\mathrm{x} \quad$ : $\mathrm{x}$-axis

y $\quad$ :y-axis

$\phi \quad$ :equivalence ratio

$\rho \quad$ :density

Subscripts

$u \quad$ :unburnt state

\section{Introduction}

Combustion oscillation occurs when the sprayed fuel burns in high-pressure combustors like gas turbine and rocket engine. It yields mechanical or thermal damages to the combustors 1), 2). Main reason of such combustion oscillation is considered to be the interference of acoustic oscillation and combustion.

It has long been considered that acoustic oscillation has an effect of diffusion promotion. Kumagai explains that the particle velocity that is induced by the acoustic oscillation enhances the diffusivity in a similar manner to turbulent diffusion ${ }^{3)}$. Beside this, the authors recently reported a new thermal convection that are generated when the density difference exist in an acoustic field ${ }^{4), 5),}$ ${ }^{6)}$. Figure 1 shows the convection that occurs when the density difference was made by local heating of the fluid in acoustic field. It was clarified that the convectional transfer played an important role in the burning enhancement of droplets in the acoustic fields. These diffusive and convective effects are considered to coexist $^{7)}$. Their influence on combustion promotion must be clarified. In this study, we employed a simple system for numerical simulation that is premixed flame propagation in the acoustic field. If the diffusion promotion effect exists, a variation in the burning velocity like turbulent combustion is expected. Thus the diffusion promotion was evaluated by the burning velocity. And the convection influences the flame shape and propagation speed, it was evaluated by the flame speed.

The experiments in microgravity were also done. Since the effect of buoyancy affects the convection field, experiments has been made in the absence of gravity.

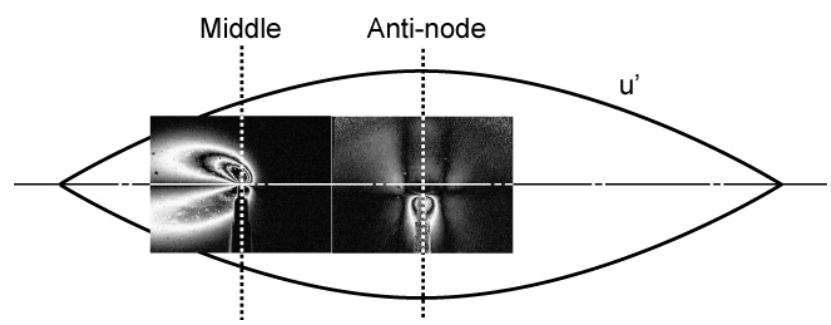

Fig. 1. Flow pattern of the convection in the acoustic field. (Schlieren image)

\section{Numerical Simulation}

The schematic of the present numerical domain is illustrated in Fig. 2. The finite difference time domain (FDTD) method was employed to simulate the time-resolved pressure-velocity field variation in the acoustic field. The size of numerical domain was same as 
combustion chamber used in the experiment. A standing acoustic field was generated by vibrating the west and east boundaries of numerical domain with sinusoidal motion. Frequency of the vibrating walls were set to 3 $\mathrm{kHz}$ to produce the sound whose wavelength is just the length of the two boundaries. The North and South boundaries were stationary wall. The acoustically induced convection for the horizontal direction becomes the strongest when the density difference is generated at the middle of velocity node and anti-node, and the convection in vertical direction does at the velocity anti-node. The diffusive effect is expected to be the strongest at the anti-node since the amplitude of the velocity fluctuation takes the maximum. These two points were chosen to be the ignition points in the present study.

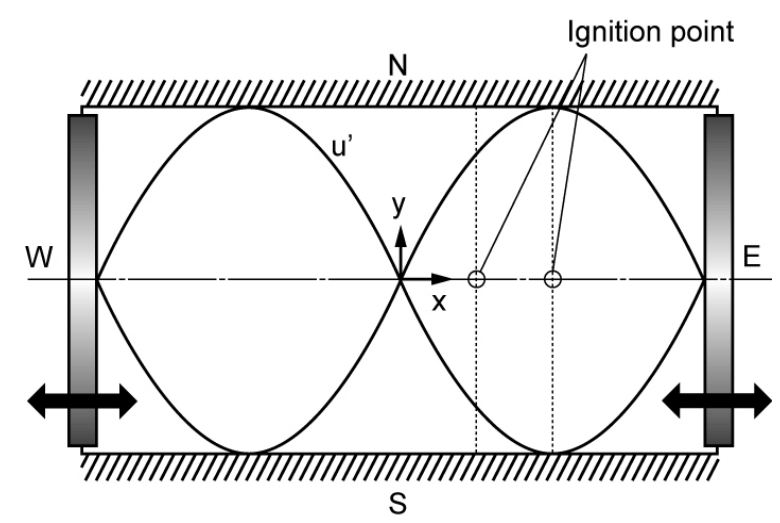

Fig. 2. Schematic view of computational domain.

An ethane-air mixture at atmospheric condition $(\mathrm{P}=0.1$ $\mathrm{MPa}, \mathrm{T}=290 \mathrm{~K}$ ) was chosen for the premixed gas. Chemical reaction was treated as the one-step global finite rate reaction whose activation energy was $125.5 \mathrm{~kJ} / \mathrm{mol}$. Equivalence ratio was set to unity and near the upper flammability limit $(\phi=1.7)$. The employed combination of equivalence ratio and sound pressure level was $\phi=1$ with SPL of $140 \mathrm{~dB}$ and $\phi=1.7$ with SPL of $150 \mathrm{~dB}$. The SPL in the former condition was frequently used in the past convection generation experiments ${ }^{8)}$. The latter condition was employed to reduce the burning velocity for the purpose to clearly observe the convective effect. Constant diffusion coefficient was used for all the species to simplify the problem. To catch up the pressure wave of sound, a time step was set to satisfy the condition that the product of the time step and sound speed is smaller than the grid pitch. In this study, the grid pitch was $0.5 \mathrm{~mm}$ and the time step was $10^{-6} \mathrm{~s}$. Adaptive grid was applied across the flame front to resolve the flame structure. The pitch of the refined grid in this grid adaptation was $1 / 16 \mathrm{~mm}$ at minimum. The employed solver was FLUENT 6.3.

\section{Burning Velocity}

The burning velocity was determined by the calculated rate of consumption of unburned gas mixture. From the mass balance across the flame front, the following equation is obtained ${ }^{9)}$.

$$
\frac{d m}{d t}=\rho_{u} S \Leftrightarrow S=\frac{1}{\rho_{u}} \frac{d m}{d t}
$$

Here, $m$ is the mass consumption per unit area, $\rho_{u}$ is the unburned gas density, and $S$ is the burning velocity.

\section{Results and Discussion}

\subsection{The convective effect in the ignition process}

Figure 3 shows the time history of the ignition point temperature during local heating of the fluid for ignition. The time origin was taken when the local heating starts. Around $20 \mathrm{~ms}$ of the graph is magnified and shown inside the original graph. From Fig. 3, negligible difference was confirmed with and without the acoustic filed from the start to $20 \mathrm{~ms}$, however, for the rapid temperature increase after $20 \mathrm{~ms}$, the difference appeared. The temperature rise with the acoustic field was faster than that of without the acoustic field. The effect of the acoustic field for ignition delay time was reported by the authors ${ }^{10)}$. In this report, the ignition delay time in the acoustic field can be long compared with that without the acoustic field. The effect contrary to the previous work was uncovered for this intense acoustic field.

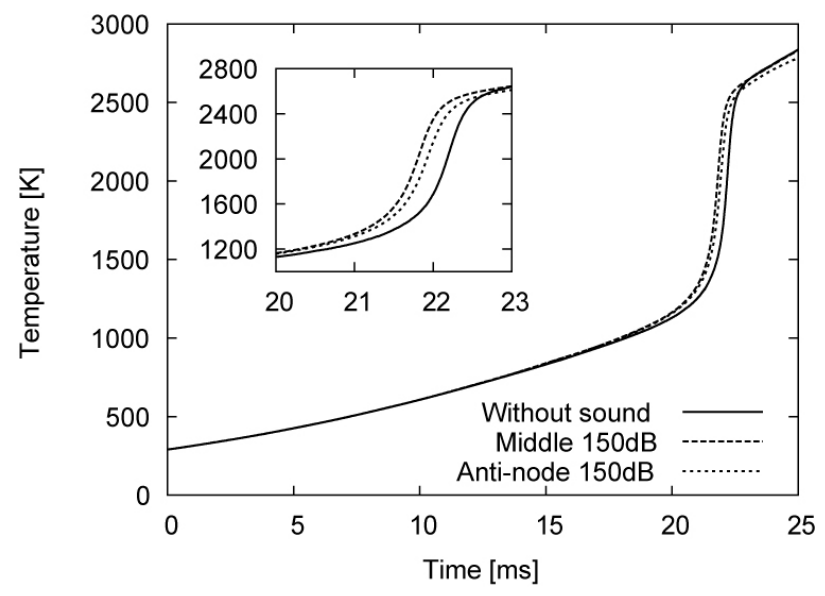

Fig. 3. Time history of ignition point temperature.

Table 1 shows the result of the ignitability tests with and without the acoustic field in the experiments. From Table 1, the mixture can be ignited with the acoustic field, while it fails to ignite without the acoustic field. The existence of the acoustic field affects the ignitability. The premixed gas was easy to ignite with the acoustic field compared to without the acoustic field.

Table 1. Ignition possibility with and without sound in the microgravity experiments. (methane, $\phi=0.55$ (near the lean flammability limit))

\begin{tabular}{|c|c|c|}
\hline & Without sound & $\begin{array}{c}\text { With sound } \\
(3 \mathrm{kHz}, 150 \mathrm{~dB})\end{array}$ \\
\hline $\begin{array}{c}\text { Ignition } \\
\text { possibility }\end{array}$ & $0 / 3$ & $2 / 2$ \\
\hline
\end{tabular}




\subsection{The convective effect for flame propagation at} the middle and the anti-node $(\phi=1, S P L=140 \mathrm{~dB})$

Figure 4 shows the high local reaction rate region that expresses the propagating flame front. The lower boarder is the axis of symmetry, only the upper part is shown in this figure. The images are taken $20 \mathrm{~ms}$ after the start of the local heating for the ignition. At this point, the flame shape was almost the same with and without acoustic field in the middle.

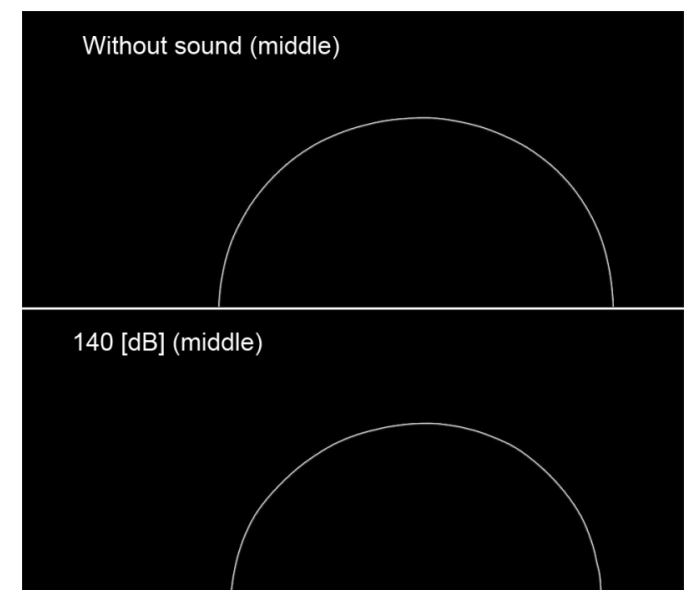

Fig. 4. Images of propagating flame front. (Time: $20 \mathrm{~ms}$, ignited at the middle, acoustic frequency: $3 \mathrm{kHz}$, SPL: $140 \mathrm{~dB}$ )

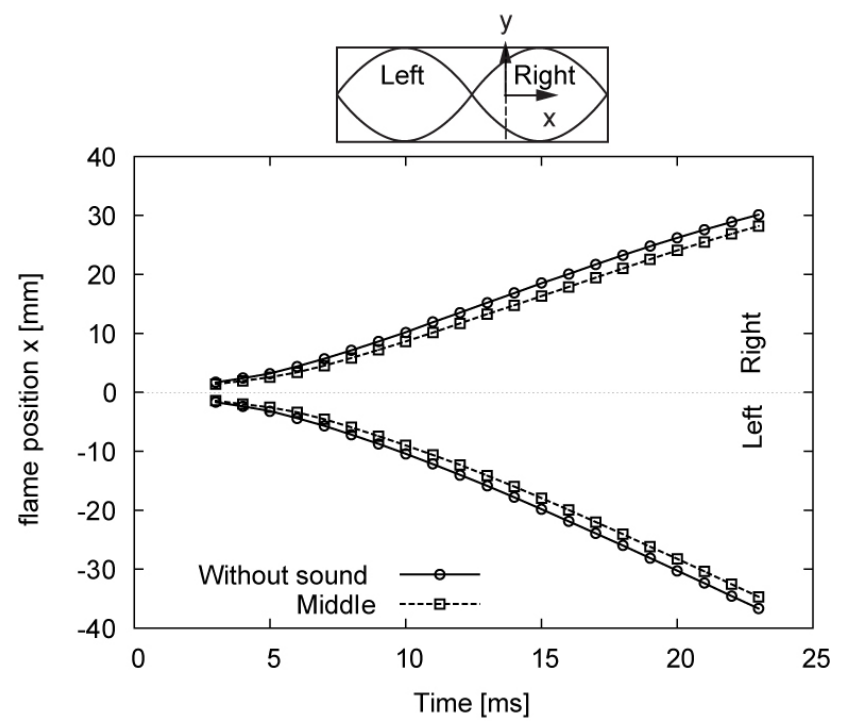

Fig. 5. Time history of propagating flame front position. (Ignited at the middle, acoustic frequency: $3 \mathrm{kHz}$, SPL: $140 \mathrm{~dB}$ )

Figure 5 shows the time history of propagating flame front position with and without the acoustic field. Time origin was the start of the local heating. There seemed to be no significant effect of the acoustic field on the flame position. Conversely the growth of the flame without the acoustic field was faster than with the acoustic field. It is considered that the difference of the flame position caused by the acoustic field is the result of the ignition delay time.
4.3. The convective and diffusive effect for flame propagation at the middle $(\phi=1.7, \mathrm{SPL}=150 \mathrm{~dB})$
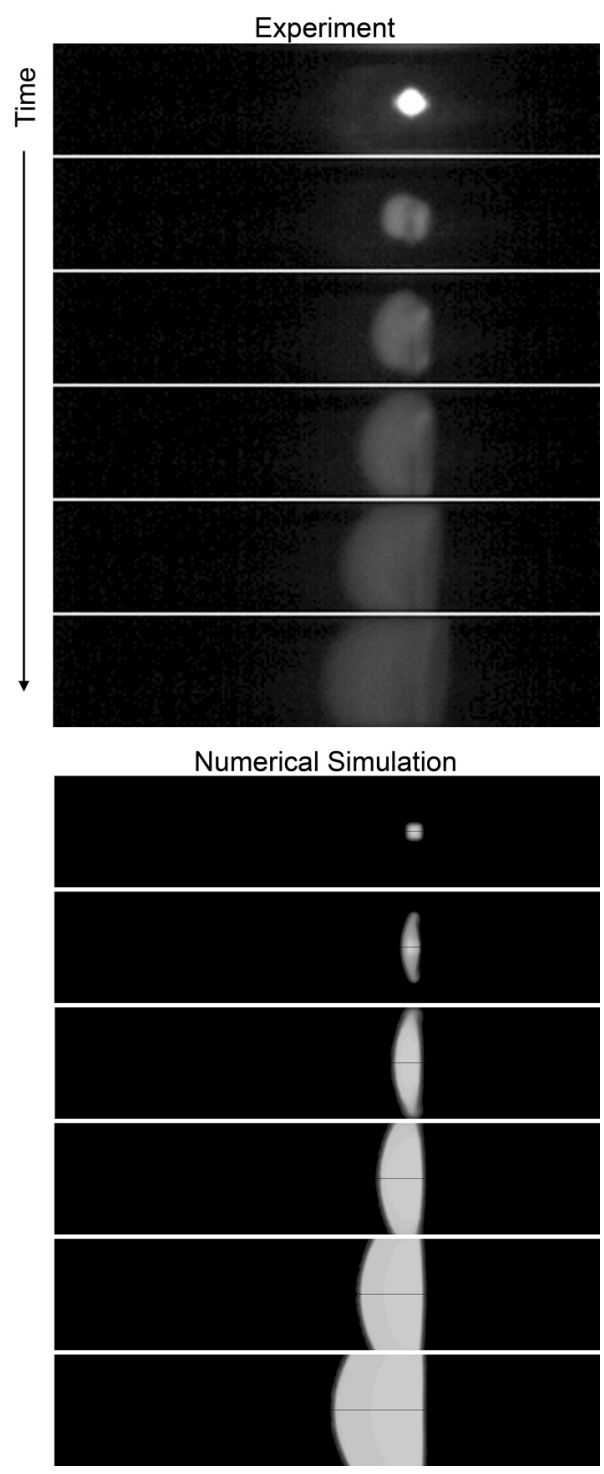

Fig. 6. Sequential image of flame shape ignited at the middle of velocity node and anti-node. (Time interval: $5 \mathrm{~ms}$, acoustic frequency: $3 \mathrm{kHz}$, SPL: $150 \mathrm{~dB}$ )

Figure 6 shows the propagating flame ignited at the middle of velocity node and anti-node that was observed in the microgravity experiments and numerical simulations. The equivalence ratio was 1.7 and SPL was $150 \mathrm{~dB}$. In the experiment, the quartz window was employed to observe the flame propagation by high-speed camera, and its size $88 \mathrm{~mm} \mathrm{X} 18 \mathrm{~mm}$. Therefore, only window part is shown in Fig. 6 for easy comparison. The flame front does not propagate under the condition of $\phi$ $=1.7$ without the acoustic field. Improvement of ignitability in the acoustic field was confirmed also in the numerical simulation. From Fig. 6, in the experiment, the flame shape was completely different from the flame propagation in microgravity without the acoustic field as 
shown in top of Fig. 4. In microgravity, the flame shape is always circular that means the propagation speed is identical for all directions. However, flame speed was not identical in the acoustic filed in microgravity. Flame shape was sector form. In the numerical simulation, the picture at the top was taken $2 \mathrm{~ms}$ after the start of local heating for ignition. The result agreed with experimental result qualitatively. The flame front was stretched in the vertical direction at the beginning. After that, the flame front propagates for the left that is the velocity node direction. Time history of the flame front position is shown in Fig. 7. In the right hand side of the ignition point, flame did not propagate and stayed near the ignition point. This flame behavior corresponds to the convection seen in the former experimental results shown in Fig. 1.

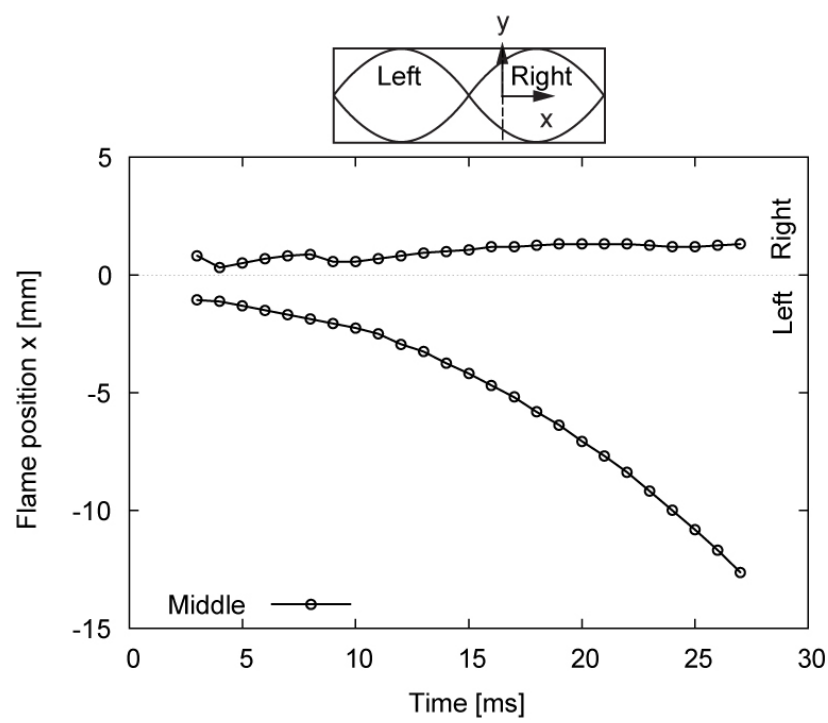

Fig. 7. Time history of propagating flame front position on the $\mathrm{x}$-axis in the middle. (Acoustic frequency: $3 \mathrm{kHz}$, SPL: $150 \mathrm{~dB}$ )

If the diffusion promotion effect exists, a rise in the burning velocity similar to the turbulent combustion would be confirmed. Thus the diffusion promotion effect was evaluated through the burning velocity that was calculated using Eq. (1). The burning velocity of the flame on the $\mathrm{x}$ and $\mathrm{y}$-axis is shown in Fig. 8. It takes the high value at the beginning in the right side. On the contrary, in the left side, it takes lower value for all. The interest thing is that the burning velocity on y-axis was always zero. The changes in the burning velocity could be confirmed.

Figure 9 shows the contour of local reaction rate at different time with the time interval of $5 \mathrm{~ms}$, the apex of flame was open. By the previous study with SPL of 143 $\mathrm{dB}^{11)}$, the apex is open at the beginning and closed later. However, in the present condition, the apex was always open.

Zero burning velocity at the apex of the flame does not mean that it was only the effect of diffusion promotion by the acoustic field. Figure 10 shows the velocity vector of the flow field. It can be considered that the burning velocity decreases by the flame stretch due to the occurrence of the thermal convection toward the apex of the flame. The existence of the diffusion promotion effect cannot be clarified from this result.

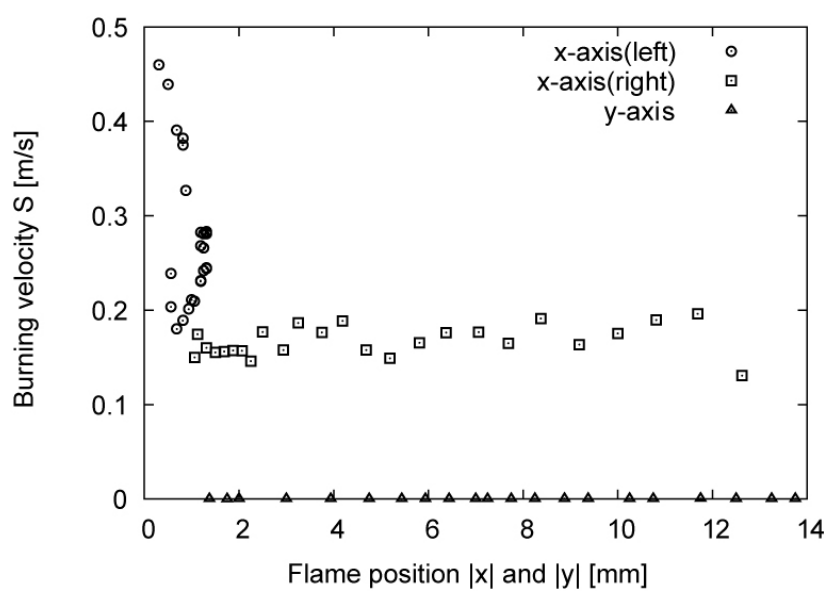

Fig. 8. The burning velocity $S$ of flame on the $\mathrm{x}$ and $\mathrm{y}$-axis ignited at the middle. (Acoustic frequency: $3 \mathrm{kHz}$, SPL: $150 \mathrm{~dB}$ )

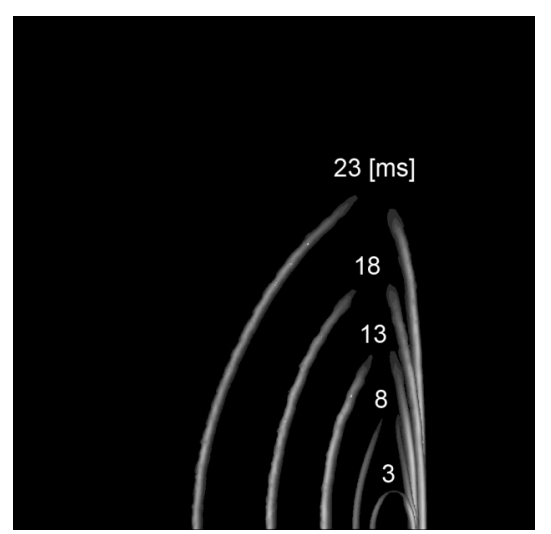

Fig. 9. Contour of local reaction rate. (Ignited at the anti-node, time interval: $5 \mathrm{~ms}$, acoustic frequency: $3 \mathrm{kHz}, \mathrm{SPL}: 150 \mathrm{~dB}$ )

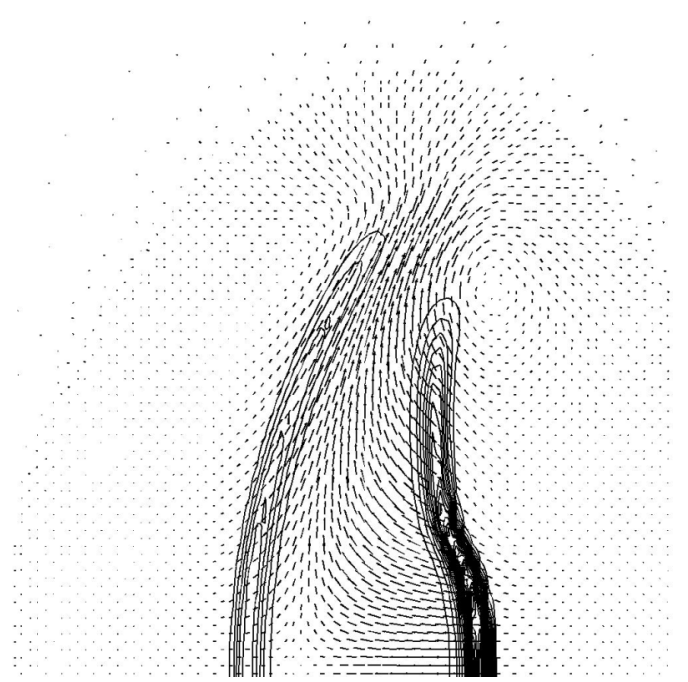

Fig. 10. Distribution of velocity vector with contour of local reaction rate. (Time: $5 \mathrm{~ms}$, middle) 
4.4. The convective and diffusive effect for flame propagation at the anti-node $(\phi=1.7, \mathrm{SPL}=150 \mathrm{~dB})$

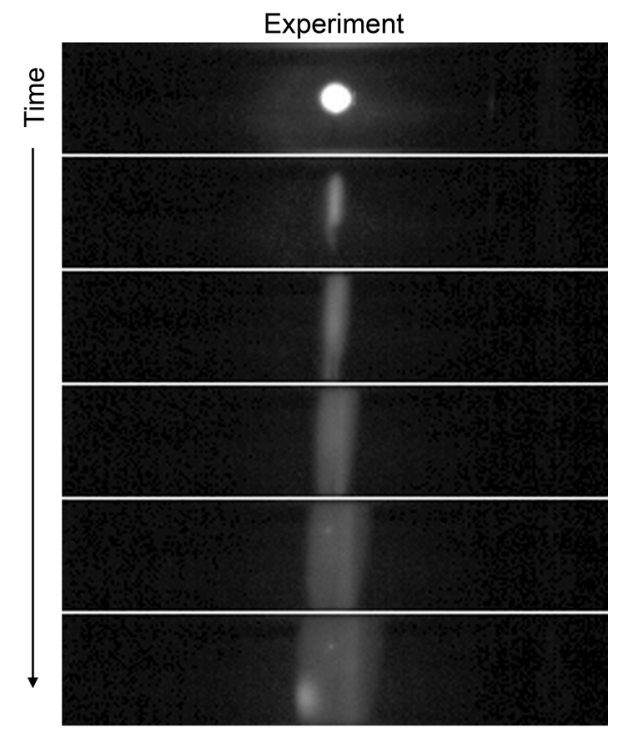

Numerical Simulation

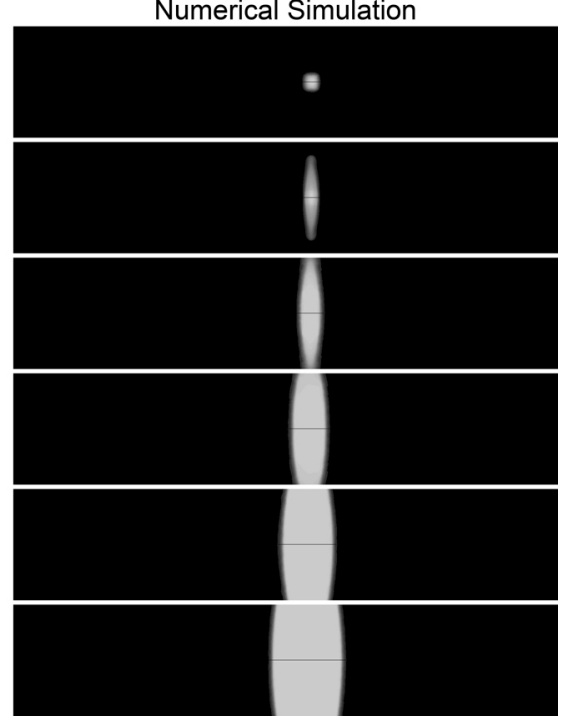

Fig. 11. Sequential images of flame shape ignited at the anti-node. (Time interval: $5 \mathrm{~ms}$, Acoustic frequency: $3 \mathrm{kHz}$, SPL: $150 \mathrm{~dB}$ )

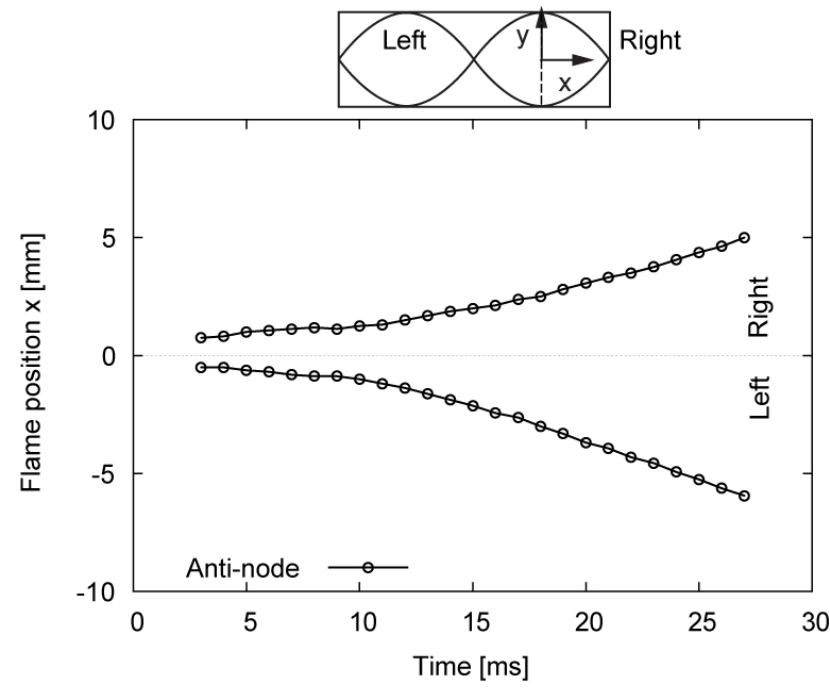

Fig. 12. Time history of propagating flame front position on the $\mathrm{x}$-axis in the anti-node. (Acoustic frequency: $3 \mathrm{kHz}$ SPL: $150 \mathrm{~dB}$ )
Figure 11 shows the propagating flame ignited at the velocity anti-node that was observed in the experiments and numerical simulations. Both results show the same behavior. Flame was strongly stretched for vertical direction consistently. Time history of the flame front position is shown in Fig. 12. The flame front position for the right and left direction was almost same.

The burning velocity on $\mathrm{x}$ and $\mathrm{y}$-axis are shown in Fig. 13. Different from the case ignited at the middle, the burning velocity was identical for the right and left direction. It is considered that the mesh resolution causes a fluctuation in the burning velocity. In the $x$-axis, the burning velocity at the beginning was high due to the heat input for ignition. In the $y$-axis, the burning velocity was always zero and the apex of flame was open as shown in Fig. 14 as well as the case ignited at the middle. The thermal convection toward the apex of the flame was confirmed also in the anti-node from Fig. 15. This thermal convection can be considered to cause the decrease in burning velocity on $y$-axis in the anti-node by the reason that is previously mentioned in Sec. 4.3.

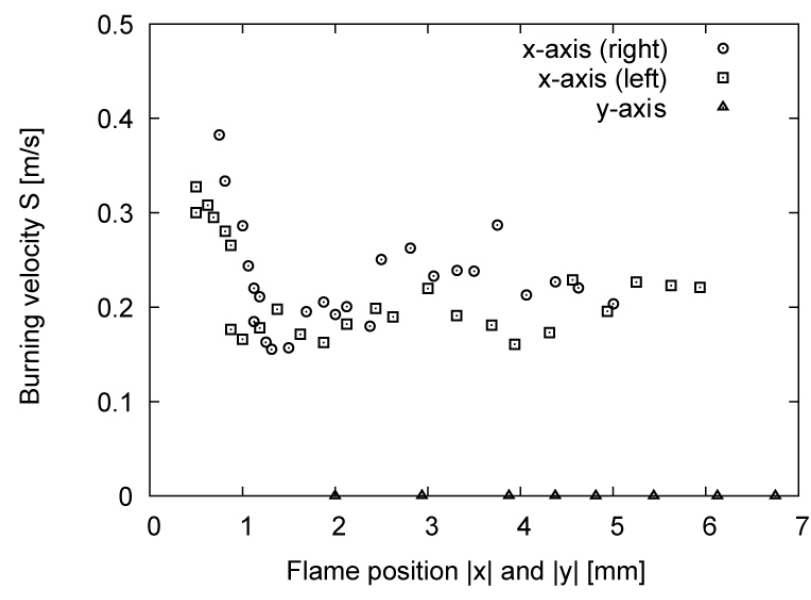

Fig. 13. The burning velocity $S$ on the $\mathrm{x}$ and $\mathrm{y}$-axis ignited at the middle. (Acoustic frequency: $3 \mathrm{kHz}, \mathrm{SPL}: 150 \mathrm{~dB}$ )

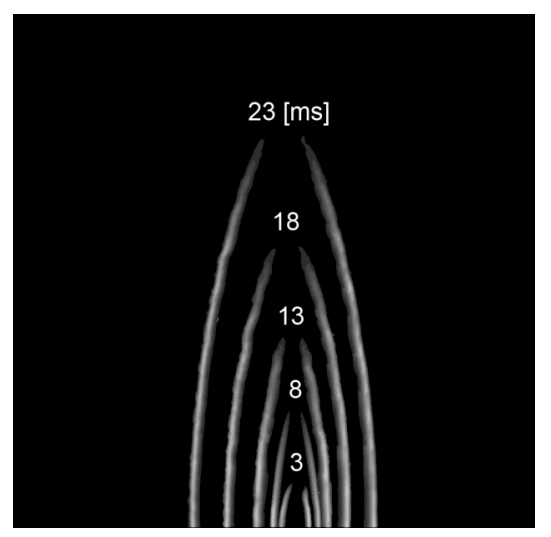

Fig. 14. Contour of local reaction rate. (Ignited at the anti-node, time interval: $5 \mathrm{~ms}$, Acoustic frequency: $3 \mathrm{kHz}$, SPL: $150 \mathrm{~dB}$ ) 


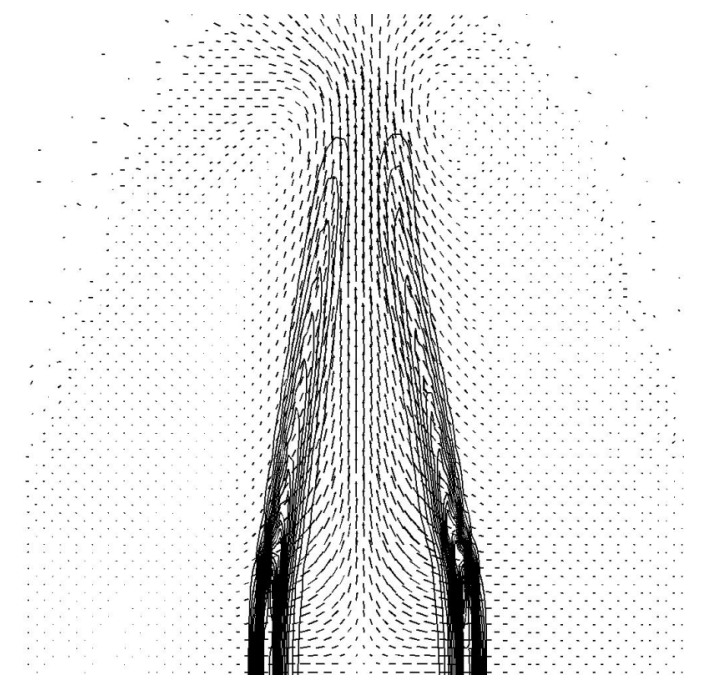

Fig. 15. Distribution of velocity vector with contour of local reaction rate. (Time: $5 \mathrm{~ms}$, anti-node)

\section{Conclusions}

From the experiments and FDTD simulations on the flame propagation in the pre-mixture, the followings were found.

The convection effect for the premixed flame propagation was not clearly observed in the condition of $\phi=1$ with SPL of $140 \mathrm{~dB}$.

The convection effect for the premixed flame propagation was clear in the condition of $\phi=1.7$ with SPL of $150 \mathrm{~dB}$. The ignition delay time could be shortened by the acoustic filed. It was considered that the ignitability changes with or without convection. The flame was expands faster toward the velocity node after the vertical expansion in the middle. On the contrary, the flame did not propagate to the opposite direction. It was found that the flame expands vertically in the anti-node.

The burning velocity was influenced through the thermal convection, however, the turbulent diffusion effect was unclear. Especially in the y-axis, the burning velocity was always zero since the apex of the flame was open. Above $150 \mathrm{~dB}$ is required to clearly observe the convective effect on the premixed flame propagation.

\section{Acknowledgements}

This study was carried out as a part of "Ground-base Research Announcement for Space Utilization" promoted by the Japan Space Forum and JAXA.

\section{References}

1) Tong, A. Y. and Sirigano, W.A.:Oscillatory Vaporization of Fuel Droplets in an Unstable Combustor, Journal of Propulsion and Power, 5, (1989), pp.257-251.

2) Duvvur, A. et al.:Oscillatory Fuel Droplet Vaporization Driving Mechanism for Combustion Instability, Journal of Propulsion and Power, 12, (1996), pp. 358-356.

3) Kumagai, S. and Hiroshi, I.:Combustion of Fuel Droplets in a Vibrating Air Field, Proceedings of the Combustion Institute, 5, (1955), pp. 129-132.

4) Tanabe, M. et al.:Influence of Standing Sound Wave on Droplet Combustion, Proceedings of the Combustion institute, 28, (2000), pp. 1007-1013.

5) Tanabe, M. et al.:Droplet Combustion in Standing Sound Wave, Proceedings of the Combustion institute, 30, (2005), pp. 1957-1964.

6) Tachi, K. et al.:Numerical Modeling of Thermo-Acoustic Streaming, Journal of JASMA, 22, (2005), pp.42-46.

7) S. Dattarjan et al.:Acoustic Excitation of Droplet Combustion in Microgravity and Normal Gravity, Combustion and Flame, 144, (2006), pp. 299-317.

8) Yamauchi, $Y$ et al.:Study on Characteristics of Thermo-Acoustic Streaming by Microgravity Experiment and Numerical Simulation, Proceedings of the $\mathbf{2 5}^{\text {th }}$ ISTS, (2006), pp. 892-897.

9) Bradley, D. et al.:Burning Velocity, Markstein Length, and Flame Quenching for Spherical Methane-Air Flames, Combustion and Flame, 104, (1996), pp. 176-198.

10) Takuma, Y.: A Numerical Study on Premixed Flame Propagation in Acoustic Field, Proceedings of the $\mathbf{4 5}^{\text {th }}$ Symposium on Combustion, (2007), pp. 124-125.

11) Tanabe, M. and Takuma, Y., ISPS, (2007), paper. 